\title{
Social Comparison and Perceived Breach of Psychological Contract: Their Effects on Burnout in a Multigroup Analysis
}

\author{
Gabriela Topa Cantisano, J. Francisco Morales Domínguez, and J. Luis Caeiro García \\ Universidad Nacional de Educación a Distancia (UNED)
}

\begin{abstract}
This study focuses on the mediator role of social comparison in the relationship between perceived breach of psychological contract and burnout. A previous model showing the hypothesized effects of perceived breach on burnout, both direct and mediated, is proposed. The final model reached an optimal fit to the data and was confirmed through multigroup analysis using a sample of Spanish teachers $(\mathrm{N}=401)$ belonging to preprimary, primary, and secondary schools. Multigroup analyses showed that the model fit all groups adequately. Keywords: perceived breach of psychological contract, social comparison, burnout, structural equation modeling, multigroup analysis
\end{abstract}

\begin{abstract}
Este estudio se centra en el papel de la comparación social en la relación entre la ruptura percibida del contrato psicológico y el burnout. Se propone un modelo previo mostrando los efectos hipotetizados, tanto directos como mediados, de la ruptura percibida sobre el burnout. El modelo final alcanzó un ajuste óptimo a los datos y se confirmó a través del análisis multigrupo usando una muestra de profesores españoles $(N=401)$ pertenecientes a escuelas infantiles, primarias y secundarias. Los análisis multigrupo mostraron que el modelo se ajusta adecuadamente a todos los grupos.

Palabras clave: ruptura percibida del contrato psicológico, comparación social, burnout, modelos de ecuaciones estructurales, análisis multigrupo
\end{abstract}

Correspondence concerning this article should be addressed to Gabriela Topa Cantisano, UNED, c/ Juan del Rosal, 10 Despacho 1.53. 28040. Madrid (Spain). E-mail: gtopa@psi.uned.es

Translation: Virginia Navascués Howard 
In the last few decades, investigators' interest in the role of social comparison in people who face some kind of threat has increased progressively. The direction of the comparison has been the main object of these works, focusing on whether individuals tend to compare themselves with those who are worse off than they are (downward comparison) or with those who are better off (upward comparison). Studies with various populations that experience threats, either from the perspective of health, such as patients with rheumatoid arthritis, cancer, infertility, and chronic pain (for a review, see Tennen, McKee, $\&$ Affleck, 2000), or from the perspective of work, such as health staff in psychiatric institutions, professional military staff, nurses, and teachers (Buunk \& Ybema, 1997, 2003; Buunk, Ybema, Gibbons, \& Ipenburg, 2001; Buunk, Ybema, Van der Zee, Schaufeli, \& Gibbons, 2001), have shown that downward comparisons are more frequent and that the perception of being better off than one's peers seems to be related to subjective well-being.

The identification and contrast model (Buunk \& Ybema, 1997) indicated that social comparison has diverse effects depending on whether people feel identified with or opposite to the people with whom they compare themselves. However, despite the renewed impulse that this perspective has contributed to studies on social comparison, there are still some deficiencies. First, most works show consistent relations but very few of them propose broader causal models (Buunk, Zurriaga, González-Roma, \& Subirats, 2003). Second, most of the works have focused on a limited range of results and have ignored antecedent variables of social comparison in specific contexts. Lastly, the empirical studies have focused on individual differences, ignoring the variables concerning the social context in which the comparison takes place.

The present study of populations by means of surveys is an attempt to correct some of these deficiencies by analyzing a model that considers certain person-context interaction variables to be the antecedents of social comparison, and it provides results on a personal level. Specifically, we analyze the mediator role of the processes of social comparison in teachers' perception of breach of psychological contract and the burnout syndrome experienced by these employees.

A psychological contract is a mutual agreement between two members of a relation about the terms of their reciprocal exchange based on a series of promises that both parts made when initiating the relation (Rousseau, 1995). This series of beliefs is gradually adjusted during the development of the work relation, helping the employee to construct the sense of reality that is new to him or her (Rousseau, 2001, 2004). Throughout this development, one of the parts may arrive at the conclusion that the other part has not fulfilled the promises, thus producing the perceived breach of the psychological contract (Robinson, 1996). The negative effects of this phenomenon are extensively documented and a recent meta-analytic review summarizes such effects as an increase in undesirable results for the person and the organization such as work dissatisfaction, negligence in task performance, and intention to quit; and, at the same time, a decrease in desirable results such as satisfaction, organizational commitment, or civil behavior (Topa \& Palací, 2004). Within this range of negative results, some studies have shown that breach of contract becomes a source of workers' burnout, partly because it threatens predictability and the sense of control that people believe they have over their environment (Gakovic \& Tetrick, 2003; Leiter, 1999; Topa \& Morales, 2005). Teacher burnout is a decrease in well-being caused by chronic work stress and characterized by emotional exhaustion, a cynical attitude towards the students, and a diminished feeling of professional efficacy. Although burnout seems prevalent among secondary teachers, studies show that it is frequent at all educational levels (Byrne, 1999). On the basis of these findings, in this study, we predict that the breach of the psychological contract will have direct influence on the three components of the burnout syndrome: emotional exhaustion, cynicism, and lack of professional efficacy.

Most of the studies on social comparison that have used professional groups assumed that these groups were under some kind of work-related threat, but they did not focus on breach of psychological contract. However, some authors have proposed that processes of social comparison are to be expected following the employees' perception of breach of contract (Morrison Wolfe, \& Robinson, 1997). By such processes, people relate their own situation to that of their peers. This comparison, while becoming the basis for researchers to identify the behaviors that are prevalent in certain social contexts (Morrison, Wolfe, \& Robinson, 1997), is also useful for the employees to adapt to the stressing situation they must deal with (Bennenbroek, Buunk, van der Zee, \& Grol, 2002). On the basis of these statements, in this study, we propose that the breach of psychological contract will affect the three components of burnout mediated by social comparison.

Traditionally, it has been noted that, under threatening circumstances, people tend to compare their situation with that of those who are worse off than they are and that this downward comparison may contribute to their well-being (for a review, see Van der Zee, Oldersma, Buunk, \& Bos, 1998). This statement is based on the assumption that people contrast their situation with that of other people in the process of comparison and this leads them to the comforting conclusion that they are doing better than the others. However, not all the studies support this direction of social comparison, as some works report that comparison with people who are worse off can have negative effects (Gibbons \& Gerrard, 1991), and it has also been shown that, in many cases, people prefer contact with those who are better off, partly because this provide them with useful information about how to solve their problems (among others, see Van der Zee et al., 1998). 
On the basis of this evidence, Buunk and Ybema (1997) proposed their identification and contrast model, arguing that the consequences of social comparison not only depend on the direction of the comparison but also on the psychological processes involved. Thus, whereas by means of contrast, people oppose their situation to that of the people with whom they compare themselves, by means of identification, they assume a future similarity with the object of comparison. It is expected that, in comparison with those who are better off, identification is comforting, and contrast causes unease, whereas in comparison with those who are worse off, the opposite pattern would be observed (Van der Zee, Buunk, Sanderman, Botke, \& van den Bergh, 2000). These authors verified that the four proposed tendencies were ultimately better classified in two basic strategies of social comparison: a tendency to focus on the negative interpretation of information, by means of downward identification and upward contrast (that is, identifying with those who are worse off and contrasting oneself with those who are better off), and a tendency of positive interpretation by means of identification with those who are better off (upward identification) and contrast with those who are worse off (downward contrast) (Van der Zee et al.).

On the basis of these findings, in this study, we predict that breach of psychological contract will have the opposite effect on the two basic dimensions of social comparison:

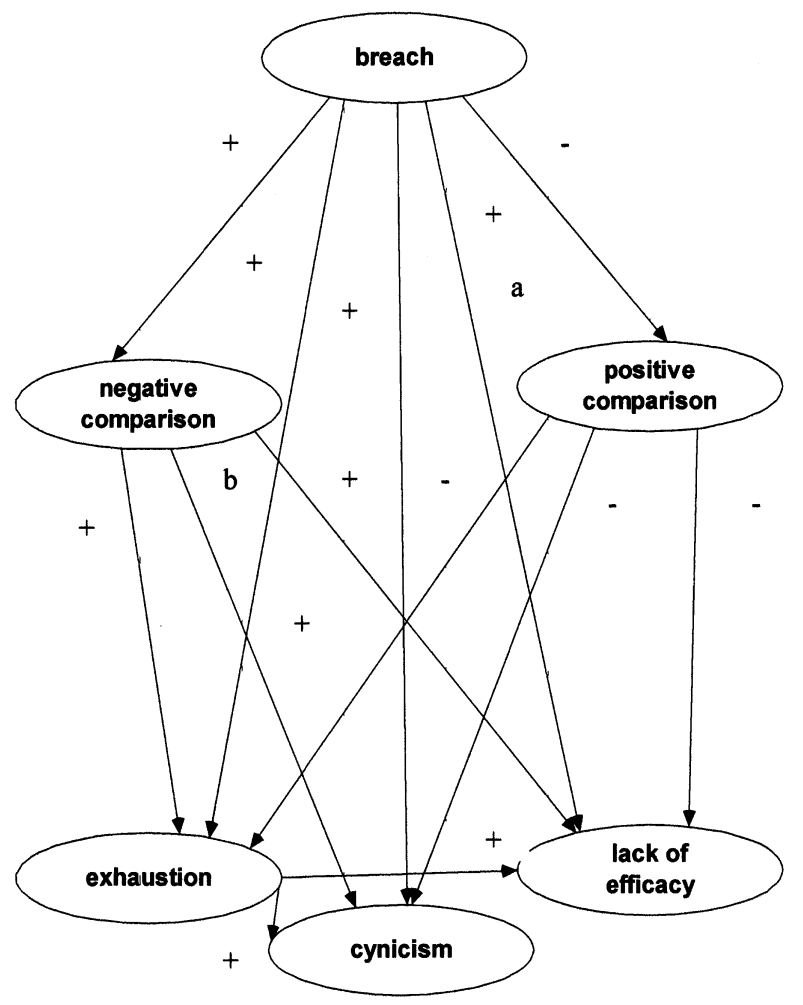

identification and contrast. Moreover, we predict that the two dimensions of comparison will have the opposite effect on the results, that is, negative comparison will have a positive influence on emotional exhaustion, cynicism, and the lack of fulfillment, whereas positive comparison will follow the opposite pattern. The predicted model is represented in Figure 1.

Summing up, in the present study, the hypotheses are as follows:

1. We expect to find direct effects of the breach of psychological contract on emotional exhaustion, cynicism, and the lack of professional efficacy.

2. We expect the effects of breach of contract on emotional exhaustion, cynicism, and lack of achievement to be mediated by positive and negative social comparison.

3. We expect to observe positive effects of negative social comparison on emotional exhaustion, cynicism, and lack of professional efficacy.

4. We expect to find negative effects of positive social comparison on emotional exhaustion, cynicism, and lack of professional efficacy.

5. Due to the similarity in conditions of teaching, we predict that this model will be adequate for teachers of preprimary, primary, and secondary educational levels.

Figure 1. Original model and re-specified model. 


\section{Method}

\section{Participants}

The sample was made up of 401 teachers from the Community of Madrid, of whom $64 \%$ were women and $36 \%$ men, working at various educational levels $(17.7 \%$ in preprimary education, $54.3 \%$ in primary education, $18 \%$ in secondary education, and $10.22 \%$ who did not provide this information). Most of them worked in public centers $(82.6 \%)$. Mean age was 37.4 years $(S D=10.4)$ and mean time in the same post was 12.4 years $(S D=10.3)$. Data were collected between the months of December of 2003 and February of 2004. Before completing the questionnaire, participants were informed about the study and the confidential nature of the data. After obtaining informed consent, they filled in a series of scales.

\section{Instruments and Procedure}

Perception of Breach of Psychological Contract. We used a global of measure of perceived contract breach (Robinson \& Morrison, 2000) which consists of 5 items that assess the participants' perceptions about how adequately the organization has fulfilled the psychological contract. The level of reliability was adequate $(\alpha=.81)$. Responses were rated on a 5-point Likert-type scale, ranging from 1 (totally disagree) to 5 (totally agree). Examples of items are: "I am annoyed because the institution for which I work has provided fewer benefits than promised" or "I am satisfied with the extent to which the institution has fulfilled its promises to me."

Social comparison. This was assessed with the scale of identification and contrast (Van der Zee et al., 2000), focusing item formulation on the comparison of work aspects. The original instrument is made up of four subscales of 3 items each (upward identification, downward comparison, downward identification, and upward comparison). The final scale had adequate reliability $(\alpha=.78)$. To confirm the bifactorial structure of the original scale, confirmatory factor analysis was employed using the raw data matrix and maximum likelihood procedure. Despite the fact that the sensitivity of the chi-square statistic for a large sample does not allow to reach the desired level of probability, the twofactor model fit the data well, as can be observed in the following goodness-of-fit indexes: $\chi^{2}(26, N=395)=$ $60.66, p<.00$; normal chi-square $(\mathrm{CMIN} / \mathrm{DF}=2.3)$; goodness of fit index $(\mathrm{GFI}=.97)$; adjusted goodness of fit index (AGFI $=.95)$; comparative fix index $(\mathrm{CFI}=.96)$; and root mean square error of approximation (RMSEA $=.05$ ). Two items with very low factor loadings were eliminated and the resulting factors were called Negative Social Comparison (downward identification-upward contrast) and Positive Social Comparison (upward identification-downward contrast). They were moderately correlated and had adequate levels of reliability ( $\alpha=.81$ and $\alpha=.70$, respectively).

Burnout syndrome. This was evaluated with a Spanish version (Salanova et al., 2000) of the Maslach Burnout Inventory (MBI; Maslach \& Jackson, 1981). This scale has 15 items with responses ranging from 1 (never) to 5 (always). The reliability of the global scale is adequate $(\alpha$ $=.87$ ), as with the three subscales $(\alpha=.83, .70$, and .80 for emotional exhaustion, cynicism, and lack of professional efficacy, respectively).

\section{Results}

The results are grouped into two sections. In the first one, the initial structural equation model was tested and re-specified until a better fit to the data was achieved. In the second section, this model was applied by means of multigroup analysis, classifying the teachers according to the educational level at which they were teaching. Descriptive statistics and the correlation matrix of the study are offered in Table 1.

Structural equations, which offer the possibility of appraising the diverse relations simultaneously, were used in order to test hypotheses 1 to 4 . As in the structural model each latent variable has only one observable indicator, which is the mean of the corresponding scale, the relations among the latent dimensions and the observable indicators were restricted to one, and the measurement errors of the model were eliminated. For the sake of clarity, neither the regression errors nor the corresponding observable variables are shown in the figures. Various indexes are suggested to test the fit of the model, such

Table 1

Descriptive Statistics and Correlations among Variables

\begin{tabular}{lllllll}
\hline Variables & $M$ & $S D$ & 1 & 2 & 3 & 4 \\
\hline 1. Breach of psychological contract & 2.7 & .73 & & & & \\
2. Negative social comparison & 2.5 & .73 & $.31^{* *}$ & & & \\
3. Positive social comparison & 2.8 & .73 & .01 & $.39^{* *}$ & & \\
4. Emotional exhaustion & 2 & .55 & $.38^{* *}$ & $.31^{* *}$ & .02 & $.52^{* *}$ \\
5. Cynicism & 1.7 & .55 & $.32^{* *}$ & $.22^{* *}$ & .05 & $.55^{* *}$ \\
6. Lack of personal efficacy & 2.5 & .59 & $.18^{* *}$ & $.21^{* *}$ & -.06 & $.32^{* *}$ \\
\hline
\end{tabular}

$* * p<.001$. 
as the Chi-square statistic and its associated level of probability. Because of the sensitivity of this statistic to the size of the sample and the deviations from normality of the data, other goodness-of-fit indexes are proposed, such as GFI, CFI, and AGFI, and it is recommended that all of them reach values near 1 . Some authors recommend values at least over .95 for these indexes. The index RMSEA is also used. Its value should not be less than .05 to indicate a good fit. When comparing models, two other indexes are also used: the Akaike information criterion (AIC) and the Browne-Cudeck criterion (BCC), which tend to penalize more complex models with worse fit and benefit more parsimonious models with lower values and a better fit to the data. In Table 2 are displayed the goodness-of-fit statistics of the model compared. The respecification procedure began by eliminating the relations among variables that do not reach statistical significance, such as the relation between breach of contract and the lack of processional efficacy, and the relation between negative comparison and cynicism, on the basis of their critical ratios (CR). The elimination of these relations (called $a$ and $b$, respectively, in the initial model) improved the fit of the model, but it did not reach optimal values until the relation between negative and positive social comparison suggested by the modification indexes of the statistical program was established.

The preceding analyses show that the hypotheses were supported by the data, except for two relations, a direct one between perceived breach of contract and lack of professional efficacy, and a relation between negative comparison and cynicism. We will comment upon this in the following section.

In order to test the fifth hypothesis, we used multigroup analysis of the structural model established in the previous step. Multigroup analysis allows one to test the invariance of the relations among variables in several participant groups. It is recommended to use groups of similar size, but in our case, our sample of primary teachers was much larger than the other two groups. As recommended (Byrne, 2001) in multigroup analysis, a model with proved adequate fit should be used at the beginning in each of the samples separately. This model is considered the base model with which the other more restrictive models are compared. In this model, empirical data matrixes were used and the analysis was performed with the maximum likelihood procedure, as it provides more stable indicators. The proposed structural model fits the preschool teachers' data notably better than it does the remaining groups', although in all cases, the model was statistically significant.

Multigroup analysis imposes successive restrictions on the regression weights, on the covariance of the latent variables, and on the covariance of the measurement errors, forcing them to remain identical in the three samples. Thus, it allows one to determine, on the basis of the increment values of $\chi^{2}$ and its associated probability level, whether the imposition of these restrictions sensibly worsens the

Table 2

Goodness-of-Fit Statistics of the Initial Model and the Re-Specified Models

\begin{tabular}{lcccccccc}
\hline Models & $\chi^{2}(d)$ & $p$ & CMIN/DF & CFI & AGFI & AIC & BCC & RMSEA \\
\hline Original model & $73.1(2)$ & .00 & 36.55 & .84 & .44 & 111.1 & 111.8 & .30 \\
Re-specified model (without paths $a$ and $b$ ) & $73.1(4)$ & .00 & 18.29 & .85 & .72 & 107.1 & 107.8 & .21 \\
Re-specified model (with path $c$ ) & $3.25(3)$ & .35 & 1.08 & .99 & .98 & 39.2 & 39.8 & .01 \\
\hline
\end{tabular}

Note. Path $a$ refers to the relation between breach of contract and the lack of professional efficacy. Path $b$ refers to the relation between negative comparison and cynicism. Path $\mathrm{c}$ refers to the relation between negative and positive social comparison (see Figure 1). CMIN/DF = normal chi-square; $\mathrm{CFI}=$ comparative fix index; $\mathrm{AGFI}=$ adjusted goodness of fit index AIC $=$ Akaike information criterion; $\mathrm{BCC}=$ Browne-Cudeck criterion; RMSEA = root mean square error of approximation.

Table 3

Goodness-of-Fit Statistics for the Multigroup Analysis

\begin{tabular}{|c|c|c|c|c|c|c|c|c|}
\hline Goodness-of-fit statistics & $\chi^{2}(d f)$ & $p$ & CMIN/DF & $\Delta \chi^{2}(d f)$ & $p$ & CFI & AGFI & RMSEA \\
\hline Base model (Preprimary) & $1.23(3)$ & .75 & .411 & & & .99 & .97 & .00 \\
\hline Base model (Primary) & $4.00(3)$ & .26 & 1.33 & & & .99 & .96 & .04 \\
\hline Base model (Secondary) & $6.01(3)$ & .11 & 2.00 & & & .97 & .81 & .12 \\
\hline Multisample analysis: model with no restrictions & $11.28(9)$ & .26 & 1.25 & & & .99 & .93 & .03 \\
\hline Model with restricted regression weights & $32.9(29)$ & .28 & 1.34 & $21.62(20)$ & .36 & .99 & .93 & .02 \\
\hline Model with restricted regression weights and covariance & $35.53(31)$ & .26 & 1.14 & $24.24(22)$ & .34 & .99 & .94 & .02 \\
\hline $\begin{array}{l}\text { Model with restricted regression weights, latent variable } \\
\text { covariance, and measurement errors covariance }\end{array}$ & 49.14 (41) & .18 & 1.19 & $37.86(32)$ & .22 & .98 & .94 & .02 \\
\hline
\end{tabular}

Note. CMIN/DF = normal chi-square; $\mathrm{CFI}=$ comparative fix index; $\mathrm{AGFI}=$ adjusted goodness of fit index; RMSEA = root mean square error of approximation. 
statistical fit of the model. When testing the models, if the value of the probability associated with the statistic exceeds $\alpha=.05$, this indicates that there is no variation among the three samples because the imposition of the restrictions does not worsen the fit of the model to the data. In Table 3 are shown the statistics of the basic model and of the multigroup analysis that allows us to state that the structural model is invariant in the three samples, both in the regression weights and in the covariance of the structural dimensions and of the residual errors. The goodness-of-fit statistics do not decrease when restrictions are imposed and the value of the probability level associated with the increment of the global statistic is never less than that of $\alpha$. On the basis of these data, the last hypothesis of the study has found partial support and the proposed model explains reasonably well the relations between perception of breach of psychological contract and burnout, mediated by negative and positive social comparison. Moreover, the model is fairly adequate for the groups of teachers from preprimary, primary, and secondary educational levels. We must also point out that some relations of the model that do not totally fit our hypothesis were found; for example, the effects of positive comparison on the results were not negative in all the subsamples, as predicted, but instead were positive some cases, although their values were low.

The standardized estimations of the models for each of the subsamples are displayed in Figures 2, 3, and 4.

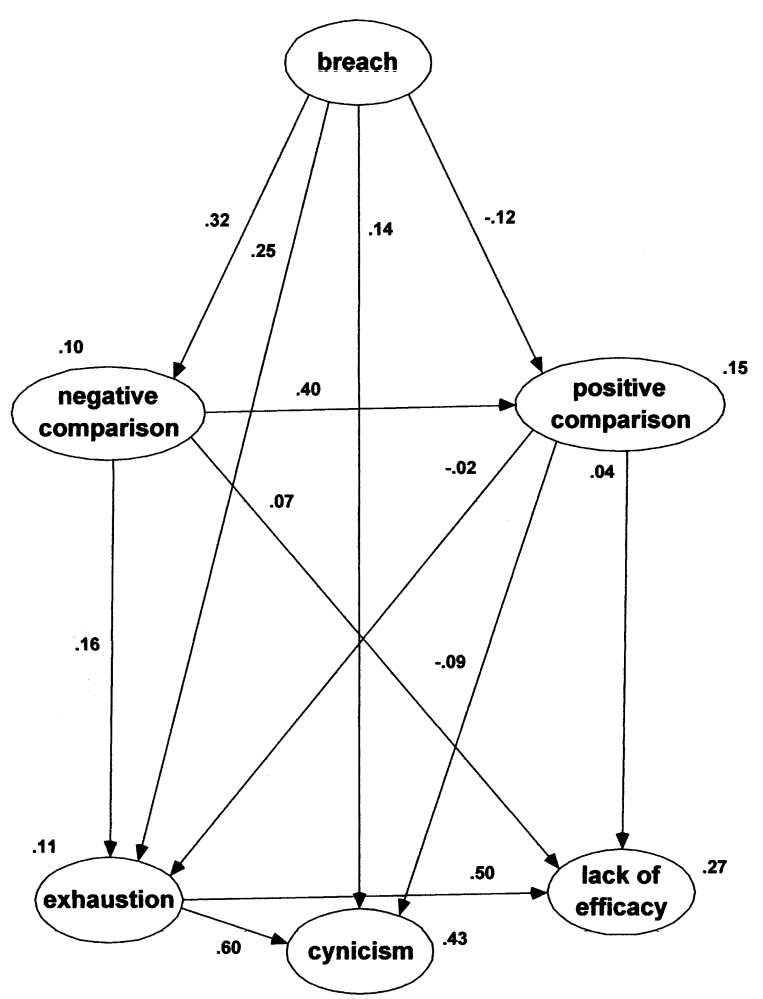

Figure 2. Standardized estimations for the model in Preprimary Education.

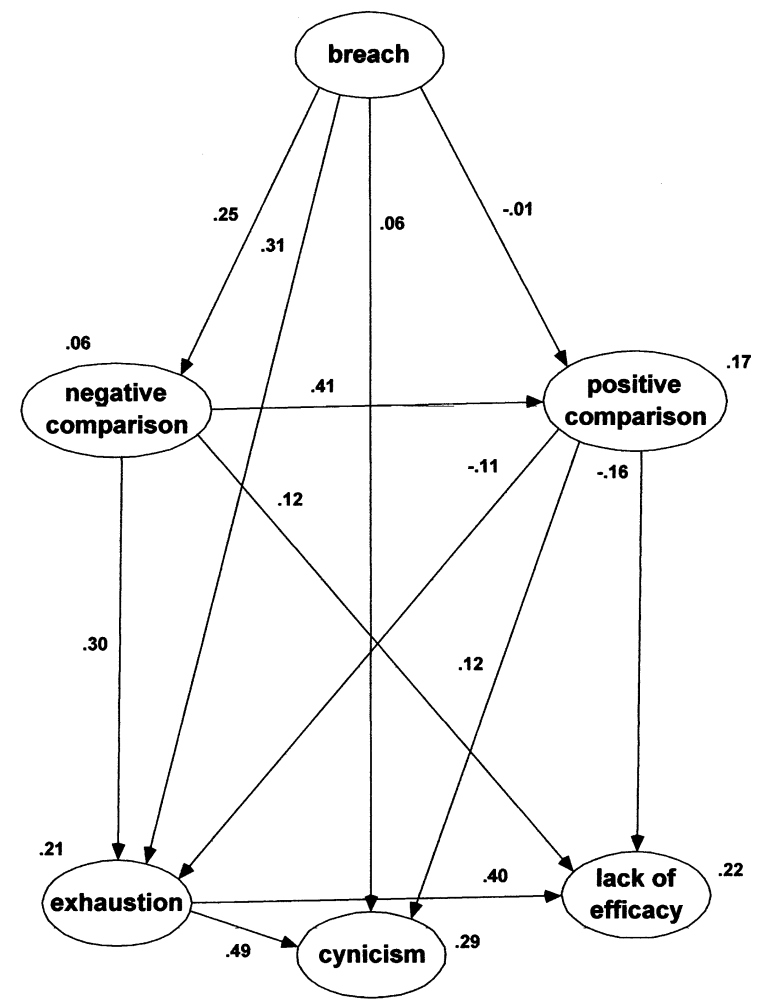

Figure 3. Standardized estimations for the model in Primary Education.

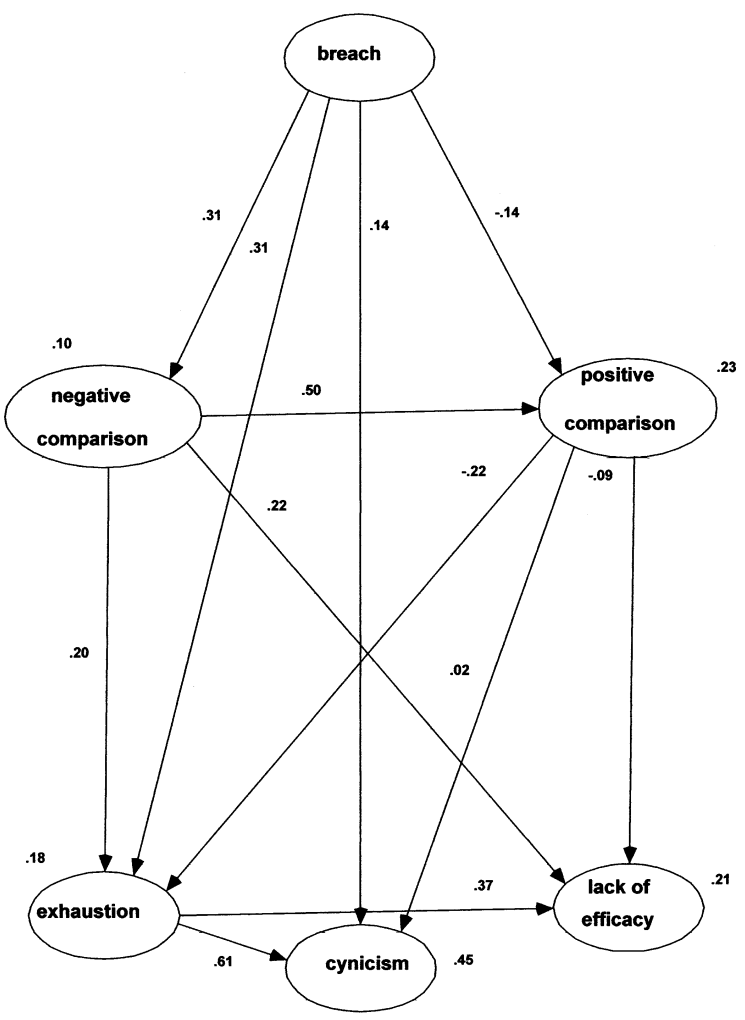

Figure 4. Standardized estimations for the model in Secondary Education. 


\section{Discussion}

Most of the results of this study are in line with the hypotheses, as the appropriateness of a general model, in which the perception of breach of psychological contract adequately predicted burnout, was verified. Moreover, it was verified that these effects are partially mediated by social comparison.

Firstly, this study found support for the affirmation (Leiter, 1999) that stated that teacher burnout is the consequence of breach of psychological contract. This statement had obtained previous empirical support in other professional collectives, such as civil servants of penitentiary institutions or intervention groups in emergencies and catastrophes (Topa \& Morales, 2005), but it had not been tested in samples of teachers.

Secondly, this study found empirical support for the theoretical affirmation that the processes of social comparison mediate between perceived breach of contract and the results. We believe this is the first work that provides data to better understand the processes that surround employees' perception that their organization has failed to satisfy its promises to them (Morrison Wolfe \& Robinson, 1997). This model assumes a proposal about the relations between burnout and social comparison that, up to a point, is new, as some studies found support for the idea that emotional exhaustion was the antecedent that led people to social comparison (Brenninkmeijer, Vanyperen, \& Buunk, 2000; Buunk, Ybema, Gibbons, et al., 2001). However, although longitudinal results are required before making statements about causalities, in this study, we tested a consistent model that seems to show that the relations could go in the opposite direction. This is not an attempt to ignore the possibility that the process may be circular, and an increase in emotional exhaustion may once more lead people to social comparison. This idea has been suggested by other authors who note that emotional exhaustion and the perception of being inferior to others reinforce each other in a circular relation (Friedman \& Farber, 1992).

Thirdly, in this study we have found that this global model is adequate for teachers of various educational levels. In this sense, despite the fact that work conditions may vary to some extent at the different levels, it seems clear that the most determining characteristics of the task of teaching are stable.

When examining the results in more detail, it can be seen that, in the general model, the influence of breach of contract on the lack of professional efficacy is not direct but mediated by the two types of social comparison, both negative and positive. These data are novel and cannot be compared with the findings of previous studies, as they either resorted to global measures of the burnout syndrome (Topa \& Morales, 2005) or else focused exclusively on the aspect of emotional exhaustion (Gakovic \& Tetrick, 2003). A feasible explanation of this fact is not obvious but it seems logical to assume that professional efficacy is a perception established by the comparison of one's work results with the results that one's colleagues were capable of achieving and, hence, one's efficacy would be more affected by social comparison than by perceived breach. It is also possible that this result will reveal a tendency to examine one's own levels of achievement when searching for explanations for perceived breach of contract, and that this examination will once more lead people to look at their work environment. As mentioned in the theoretical development (Morrison Wolfe \& Robinson, 1997), it is highly likely that, when facing organizational breach of psychological contract and searching for an explanation for this disconcerting and aversive fact, workers will engage in processes of appraisal of their own contributions along with processes of social comparison. Although theoretical speculations have suggested that these processes are simultaneous, the relations between them are probably more complex than has been initially assumed. Summing up, if workers perceive breach of contract, they will simultaneously ask "Why is this happening to me?" "How are they treating my colleagues?" and "How am I responding to the organization?" In their search for answers to these questions, social comparison will provide the clues to appraise their own lack of professional efficacy and the results that other colleagues achieve. In this sense, the direct relation predicted between negative comparison and cynicism was not confirmed in the data. Taking into consideration preceding studies, one might suppose that cynicism is the burnout syndrome dimension with the weakest relation to social comparison because it most clearly represents the cognitive aspects of psychological well-being (cynicism considered a distant attitude towards work in the case of burnout; Salanova et al., 2000 ), whereas the influence it receives from breach of contract is overwhelming. Lastly, when examining the standardized estimations for each of the separate multigroup models, it can be observed that, in preprimary education, both positive and negative social comparison seem to have little effect on cynicism and lack of efficacy. Their influence is only considerable on the dimension of emotional exhaustion. In primary and secondary education, the impact of negative social comparison on the results and, to a lesser extent, of positive social comparison, is more pronounced. In the group of primary teachers, we detected a relation between positive comparison and cynicism, but of the opposite sign from the predicted one. This was also present in secondary teachers, although its value is very low. Likewise, we observed results in the opposite direction from the predicted one in the relations between positive comparison, emotional exhaustion, and lack of professional efficacy, although, once again, the standardized regression weights were very low. In any case, it seems clear that support for the last hypothesis is only partial and that the consequences of positive comparison on personal results are not as consistent as expected across the subsamples. 
Lastly, this study ex-establishes the importance of peoples' social identity with regard to social comparison. As noted recently (Hogg, 2000), social comparisons occurring within groups are probably oriented towards reducing uncertainty rather than towards emphasizing one's own personal prominence, and moreover, they are probably comparisons with those who are better off, in the comparison dimension, that is, the so-called upward comparisons. This could explain why, in the models of this study for each educational level, the weight of positive social comparisona dimension made up almost exclusively of items of downward contrast-had little influence on the results. In contrast, the so-called dimension of negative comparisonmade up of more items of upward comparison-seemed to have more influence on the results. The teachers within each group tended to compare themselves only with members of their own group, and mainly in order to reduce uncertainty, looking for the prototypical group members as referents. On the basis of this, we suggest that, in future studies, investigators should explore in more detail the relations between these two aspects of people's relations within groups.

The following two main limitations of this study are noted: the use of a cross-sectional design, which is not the most adequate to appraise causal mechanisms in the relations among predictors and results, and resorting exclusively to self-report data. Longitudinal studies and contrasting the information with objective data from sick-leave or absenteeism reports are suggested for future studies, as well as the need to extend the sample to make it more representative. It would be worthwhile to be able to count on the support of the educational institutions, which, in general, were not eager to facilitate the access of social psychology researchers to this body of employees. Despite these limitations, we believe that this study can improve the understanding of the antecedents of the physical and psychological well-being of the workers of these collectives.

\section{References}

Bennenbroek, F.T.C., Buunk, B.P., van der Zee, K.I., \& Grol, B. (2002). Social comparison and patient information: What do cancer patients want? Patient Education \& Counseling, 47, 5.

Brenninkmeijer, V., Vanyperen, N.W., \& Buunk, B.P. (2000). I am not a better teacher, but others are doing worse: Burnout and perceptions of superiority among teachers. Social Psychology of Education, 4, 259-274.

Buunk, B.P., \& Ybema, J.F. (1997). Social comparisons and occupational stress: The identification-contrast model. In B.P. Buunk \& F.X. Gibbons (Eds.), Health, coping, and well-being: Perspectives from social comparison theory (pp. 359-388). Hillsdale, NJ: Erlbaum.

Buunk, B.P., \& Ybema, J.F. (2003). Feeling bad, but satisfied: The effects of upward and downward comparison upon mood and marital satisfaction. British Journal of Social Psychology, 42, 613-628.

Buunk, B.P., Ybema, J.F., Gibbons, F.X., \& Ipenburg, M. (2001). The affective consequences of social comparison as related to professional burnout and social comparison orientation. European Journal of Social Psychology, 31, 337-351.

Buunk, B.P., Ybema, J.F., Van der Zee, K., Schaufeli, W.B., \& Gibbons, F.X. (2001). Affect generated by social comparisons among nurses high and low in burnout. Journal of Applied Social Psychology, 31, 1500-1520.

Buunk, B.P., Zurriaga, R., González-Roma, V., \& Subirats, M. (2003). Engaging in upward and downward comparisons as a determinant of relative deprivation at work: A longitudinal study. Journal of Vocational Behavior, 62, 370-388.

Byrne, B. (1999). The nomological network of teacher burnout: A literature review and empirically validated model. In R V.M. Huberman (Ed.), Understanding and preventing teacher burnout (pp. 15-37.). New York: Cambridge University Press.

Byrne, B. (2001). Structural equation modeling with AMOS, EQS, and LISREL: Comparative approaches to testing for the factorial validity of a measuring instrument. International Journal of Testing, 1, 55-86.

Friedman, I., \& Farber, B. (1992). Professional self-concept as a predictor of teacher burnout. Journal of Educational Research, $86,28-35$.

Gakovic, A., \& Tetrick, L.E. (2003). Psychological contract breach as a source of strain for employees. Journal of Business \& Psychology, 18, 235-246.

Gibbons, F.X., \& Gerrard, M. (1991). Downward comparison and coping with threat. In J.S.T. Wills (Ed.), Social comparison: Contemporary theory and research (pp. 316-346.). Hillsdale, NJ: Erlbaum.

Hogg, M.A. (2000). Social identity and social comparison. In J.S.L. Wheeler (Ed.), Handbook of social comparison: Theory and research (pp. 401-421). New York: Kluwer Academic.

Leiter, M. (1999). Burnout among teachers as a crisis in psychological contracts. In R. Vandenberghe \& A. Huberman (Ed.), Understanding and preventing teacher burnout. (pp. 202210). New York: Cambridge University Press.

Maslach, C., \& Jackson, S.E., 1981. The measurement of experienced burnout. Journal of Occupational Behavior, 2, 99-113.

Morrison Wolfe, E., \& Robinson, S. (1997). When employees feel betrayed: A model of how psychological contract violations develop. Academy of Management Review, 22, 226-256.

Robinson, S. (1996). Trust and breach of the psychological contract. Administrative Science Quarterly, 41, 576- 599.

Robinson, S., \& Morrison, E.W. (2000). The development of psychological contract breach and violation: A longitudinal study. Journal of Organizational Behavior, 21, 525-546.

Rousseau, D. (1995). Psychological contracts in organizations. Understanding written and unwritten agreements. London: Sage.

Rousseau, D. (2001). Schema, promise and mutuality: The building blocks of the psychological contract. Journal of Occupational and Organizational Psychology, 74, 511-541. 
Rousseau, D. (2004). Psychological contracts: Understanding the ties that motivate. Academy of Management Executive, 18, 120127.

Salanova, M., Schaufeli, W., Llorens, S., Peiró, J., \& Grau, R. (2000). Desde el burnout al engagement. ¿Una nueva perspectiva? Revista de Psicología del Trabajo y de las organizaciones, 16, 117 - 134.

Tennen, H., McKee, T.E., \& Affleck, G. (2000). Social comparison processes in health and illness. In J. Suls \& L. Wheeler (Eds.), Handbook of social comparison: Theory and research (pp. 443-483). New York: Kluwer Academic.

Topa, G., Fernández, I., \& Lisbona, A. (2005). Ruptura de contrato psicológico y burnout en Equipos de intervención en emergencias y catástrofes. Ansiedad y Estrés, 11, 265-279.

Topa, G., \& Morales, F. (2005). Determinantes específicos de la satisfacción laboral, el burnout y sus consecuencias para la salud: Un estudio exploratorio con funcionarios de prisiones. (Specific determinants of work satisfaction, burnout and health consequences: An exploratory study among prison officers) International Journal of Psychology and Psychological Therapy, 5, 71-81.

Topa, G., \& Palací, F. (2004). ¿Ruptura o cumplimiento del contrato psicológico? Una revisión meta-analítica de la investigación empírica. Acción Psicológica, 3, 155-171.

Van der Zee, K., Buunk, B.P., Sanderman, R., Botke, G., \& van den Bergh, F. (2000). Social comparison and coping with cancer treatment. Personality and Individual Differences, 28, 17-34.

Van der Zee, K., Oldersma, F., Buunk, B.P., \& Bos, D. (1998). Social Comparison preferences among cancer patients as related to neuroticism and social comparison orientation. Journal of Personality \& Social Psychology, 75, 801-810.

Received December 30, 2005

Revision received September 14, 2006 Accepted September 20, 2006 